\title{
A COMPARATIVE STUDY OF THE ANALGESIC EFFECT OF TWO DOSES OF NALBUPHINE AS AN ADJUVANT TO BUPIVACAINE IN BRACHIAL PLEXUS BLOCK
}

\author{
Savitri Durgaprasad Kabade1, Sijo Sebastian², Elizabeth Wilson ${ }^{3}$ \\ ${ }^{1}$ Associate Professor, Department of Anaesthesiology, Karnataka Institute of Medical Sciences, Hubballi, Karnataka. \\ ${ }_{2}^{2}$ Postgraduate Student, Department of Anaesthesiology, Karnataka Institute of Medical Sciences, Hubballi, Karnataka. \\ ${ }_{3}^{3}$ Postgraduate Student, Department of Anaesthesiology, Karnataka Institute of Medical Sciences, Hubballi, Karnataka.
}

\section{ABSTRACT}

\section{BACKGROUND}

Various adjuvants augment efficacy of local anaesthetics by reducing dose, adverse reactions and prolonging postoperative analgesia. Nalbuphine, as an adjuvant in peripheral nerve blocks, especially Supraclavicular Brachial Plexus Block, a preferred technique is not much studied, hence this study.

Our study was done to compare analgesic effect of nalbuphine in two different doses, $(0.1 \mathrm{mg} / \mathrm{kg}) \mathrm{vs} .(0.2 \mathrm{mg} / \mathrm{kg}) \mathrm{as}$ an adjuvant to $0.5 \% 30 \mathrm{~mL}$ bupivacaine in supraclavicular brachial plexus block and study its side effects and complications in patients undergoing upper arm surgery.

\section{MATERIALS AND METHODS}

This is a prospective, comparative, randomised, double-blinded study. All patients of study group were randomly assigned into one of the three groups with sample size of 30 in each group. Two test group received $0.1 \mathrm{mg} / \mathrm{kg}$ and $0.2 \mathrm{mg} / \mathrm{kg}$ of nalbuphine, while third group received $5 \mathrm{~mL}$ of normal saline as adjuvant to $30 \mathrm{~mL}$ of $0.5 \%$ bupivacaine for Supraclavicular Brachial Plexus Block. Anaesthetist was blinded to treatment groups and observer blinded to nature of drug given. Patient outcomes in terms of duration of postoperative analgesia, durations and quality of sensory, motor blockade and adverse effects were recorded and subjected to statistical analysis. Statistical analysis was done by using SPSS 21 computer program software.

\section{RESULTS}

Addition of $0.1 \mathrm{mg} / \mathrm{kg}$ and $0.2 \mathrm{mg} / \mathrm{kg}$ nalbuphine to bupivacaine in supraclavicular brachial plexus block is associated with a significant increase in the duration of both sensory and motor block.

\section{CONCLUSION}

Nalbuphine added to bupivacaine for supraclavicular brachial plexus block in both doses are equipotent and resulted in prolongation of analgesia, reduced requirement of rescue analgesic in postoperative period without any appreciable adverse effect.

\section{KEYWORDS}

Nalbuphine, Brachial Plexus Block, Bupivacaine, Postoperative Analgesia.

HOW TO CITE THIS ARTICLE: Kabade SD, Sebastian S, Wilson E. A comparative study of the analgesic effect of two doses of nalbuphine as an adjuvant to bupivacaine in brachial plexus block. J. Evolution Med. Dent. Sci. 2018;7(18):2235-2239, DOI: $10.14260 /$ jemds/2018/503

\section{BACKGROUND}

Supraclavicular block is a regional anaesthesia technique superior to general anaesthesia for upper extremity surgeries since it avoids polypharmacy, stress of laryngoscopy, intubation, postoperative nausea, vomiting and pain. ${ }^{1}$ Brachial plexus block can be safely achieved by supraclavicular approach, as it contains fascial sheath extending from neck to axilla. ${ }^{2}$

Local anaesthetics alone for Brachial Plexus Block provides good operative conditions, but have a shorter duration of postoperative analgesia. Hence, various adjuvants such as opioids ${ }^{3}$ like Morphine, Fentanyl, Bupregesic, Nalbuphine, Pethidine, Tramadol and non-opioids like Clonidine, ${ }^{4}$ Neostigmine, Dexamethasone, ${ }^{5}$ Midazolam 6 and

'Financial or Other Competing Interest': None.

Submission 05-02-2018, Peer Review 14-04-2018,

Acceptance 20-04-2018, Published 30-04-2018.

Corresponding Author:

Dr. Savitri Durgaprasad Kabade,

House No. 64, Srujan,

Akshay Colony Phase I, Chetana College Road,

Hubballi-5850030, Karnataka.

E-mail: sdkabade20@gmail.com

DOI: $10.14260 /$ jemds/2018/503

\section{(c) (i) $(9)$}

Magnesium ${ }^{7}$ have been added to local anaesthetics in brachial plexus block to achieve quick, dense and prolonged block.

Analgesia achieved bupivacaine is by blocking the conduction of pain signals to the dorsal horn, but carries dose-dependent systemic toxicity. Various adjuvants are used to decrease the total volume of local anaesthetic and augment the analgesic effects and duration of the block. ${ }^{8}$ Nalbuphine, derivative of 14-hydroxymorphine, is an agonist-antagonist opioid, acting on $\mu(\mathrm{mu})$ receptors as antagonist and $\mathrm{k}$ (Kappa) receptors as agonist with an analgesic potency equal to morphine, while its antagonistic potency being $1 / 4^{\text {th }}$ of that of naloxone approximately. ${ }^{9}$ Unlike morphine, it exhibits a ceiling effect on respiratory depression. ${ }^{10}$ Nalbuphine can increase $\mu$-opioid based analgesia and simultaneously decrease the side effects of $\mu$-opioid.11

Despite known benefits of Nalbuphine, we did not find much literature regarding efficacy of Nalbuphine as an adjuvant to local anaesthetics in peripheral nerve blocks. Hence, this study aimed to compare the analgesic effect of Nalbuphine in two different doses, $(0.1 \mathrm{mg} / \mathrm{kg})$ vs. $(0.2$ $\mathrm{mg} / \mathrm{kg}$ ) as an adjuvant to $0.5 \% 30 \mathrm{~mL}$ Bupivacaine in supraclavicular approach for brachial plexus block and also to compare side effects and complications of Nalbuphine in patients undergoing upper arm surgery. 


\section{MATERIALS AND METHODS}

After obtaining Institutional Ethical Committee approval, this prospective, comparative, randomised, double-blinded study was conducted over a period of one year. All patients belonging to ASA 1 and ASA 2 of both sexes in the age group of 15 - 75 years undergoing upper limb surgeries at our institute were included in our study. Sample size was taken as per our convenience. Total of 90 patients were selected and were randomly assigned into one of the following three groups: Randomisation was achieved by random allocation cards using computer generated random numbers-

1. Group $\mathbf{N} 1(n=30)$ Patients: Received $30 \mathrm{~mL}$ of $0.5 \%$ Bupivacaine $+0.1 \mathrm{mg} / \mathrm{kg}$ Nalbuphine by supraclavicular route.

2. Group $\mathbf{N} 2(\mathbf{n}=\mathbf{3 0})$ Patients: Received $30 \mathrm{~mL}$ of $0.5 \%$ Bupivacaine $+0.2 \mathrm{mg} / \mathrm{kg}$ Nalbuphine by supraclavicular route.

3. Group B (n= 30) Patients: Received $30 \mathrm{~mL}$ of $0.5 \%$ Bupivacaine $+5 \mathrm{~mL}$ of Normal Saline.

After obtaining informed written consent, each patient underwent preoperative assessment along with detailed explanation of VAS score.

Inj. Midazolam $1 \mathrm{mg}$ was given as premedication, half an hour before surgery. Upon arrival in the operation room, baseline heart rate, blood pressure and oxygen saturation of each patient were recorded. Intravenous line with 18-gauge cannula obtained in the opposite limb and ringer lactate was started. Subcutaneous injection with $1 \mathrm{~mL}$ of $1 \%$ lignocaine was administered at the needle insertion site.

All the patients, as per their group received a pre-fixed combination of drugs for brachial plexus block through the supraclavicular approach with the aid of a nerve locator by an experienced anaesthesiologist. The study drug solutions were in similar volume to maintain the blindness of study and were prepared by a pharmacist who was not involved for data collection of the patients. The anaesthesiologist performing supraclavicular block was unaware of the constituent of the drug and allotment of the group and similarly resident doctors keeping records of different parameters were also unaware of group allotment. Thus, blinding was properly maintained.

\section{Parameters Monitored}

Intraoperatively, the following parameters were monitored continuously, and the observations were recorded every 5 minutes for first 30 minutes, thereafter every 10 minutes upto 1 hour and every 15 minutes till end of surgery. Postoperatively, monitoring was done every hour for 24 hours. Intraoperatively, the following parameters were monitored continuously and recorded:

1. Pulse Rate.

2. Non-Invasive Blood Pressure.

3. Electrocardiograph.

4. $\mathrm{Sp}_{2}$.

5. Respiratory Rate.

\section{Primary Outcome Measures}

Duration of Postoperative Analgesia.

\section{Secondary Outcome Measures}

1. Onset and Duration of Sensory Blockade.
2. Onset and Duration of Motor Blockade.

3. Quality of Block.

4. Evidence of any Complications.

\section{Duration of Postoperative Analgesia}

Duration of postoperative analgesia is the time of injection of drug to the patient, till the patient complains of pain and receives an analgesic dose. Patients were assessed for duration of postoperative analgesia as per Visual Analog Scale of $0-10$. The VAS score was recorded postoperatively every 60 mins till the score of 5 and more. The time of administration of rescue analgesia given in the form of Diclofenac Sodium (1.5 mg/kg) intramuscular (IM) at the VAS of 5 and/or more was noted.

\section{Onset of Sensory Blockade}

Onset of Sensory Block is the time taken from the completion of the injection of the study drug to first loss of pinprick sensation in C5 - T1 dermatomes using a blunt needle. The sensory blockade was assessed every 3 mins for the initial 30 mins following onset of sensory anaesthesia. Complete sensory block was considered when there was a complete loss of sensation to pinprick. Sensory block was graded as:

1. Grade 0: Sharp Pin Sensation.

2. Grade 1: Analgesia and/or Dull Sensation.

3. Grade 2: Anaesthesia or no Sensation.

\section{Duration of Sensory Block}

The duration of sensory block was considered as the time interval between the onset of sensory anaesthesia and the complete resolution of anaesthesia of all nerves.

\section{Motor Blockade}

Assessment of Motor Blockade was evaluated at 5 mins intervals and carried out by the same observer. Motor Blockade was evaluated by the ability to flex the elbow and hand against gravity and graded as:

1. Grade 1: Ability to flex and extend the forearm.

2. Grade 2: Ability to flex or extend only the wrist and fingers.

3. Grade 3: Ability to flex or extend only the fingers.

4. Grade 4: Inability to move the forearm, wrist and fingers.

\section{Duration of Motor Block}

The Duration of Motor Block was the time interval between the end of local anaesthetic administration and the recovery of complete motor function of the hand and forearm.

\section{Quality of Block}

At the conclusion of the procedure, quality of operative conditions will be assessed according to the following scale:

1. Grade 4 (Excellent): Patient comfortable.

2. Grade 3 (Good): Mild pain, no need for supplemental analgesia.

3. Grade 2 (Moderate): Moderate pain requiring supplemental analgesia.

4. Grade 1 (Unsuccessful): Severe pain, requiring general anaesthesia.

All patients were observed for adverse effects like nausea, vomiting, dizziness, pruritus, bradycardia, hypotension, dryness of mouth, headache and complications like 
pneumothorax, haematoma, anaphylactic reactions and postblock neuropathy in the perioperative period.

\section{Statistical Analysis}

Statistical analysis is done using SPSS 21 version software. Continuous variables were presented as means and standard deviation. ANOVA is used for multiple group comparison. Categorical variables were analysed using the Pearson's Chisquare test. Statistical significance was considered if $p$-value was less than 0.05 .

\section{RESULTS}

Patients of three groups were comparable with respect to their demographic profile as regards to age, sex distribution and duration of surgery [Figure 1,2].

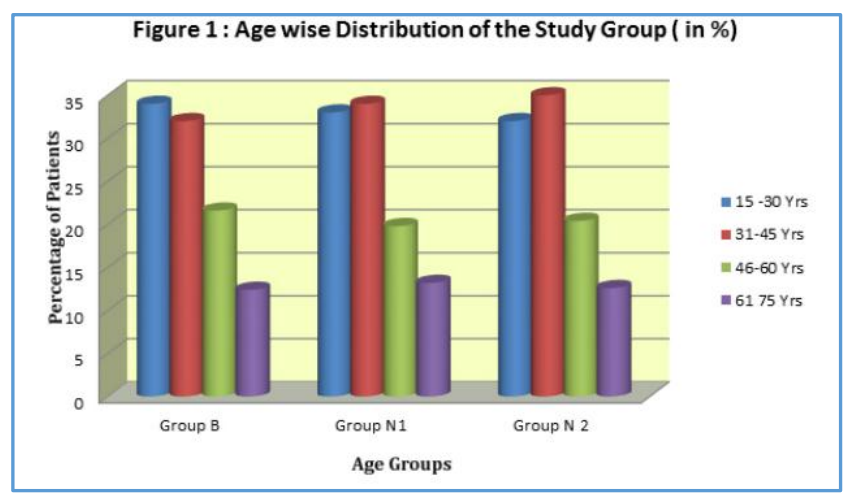

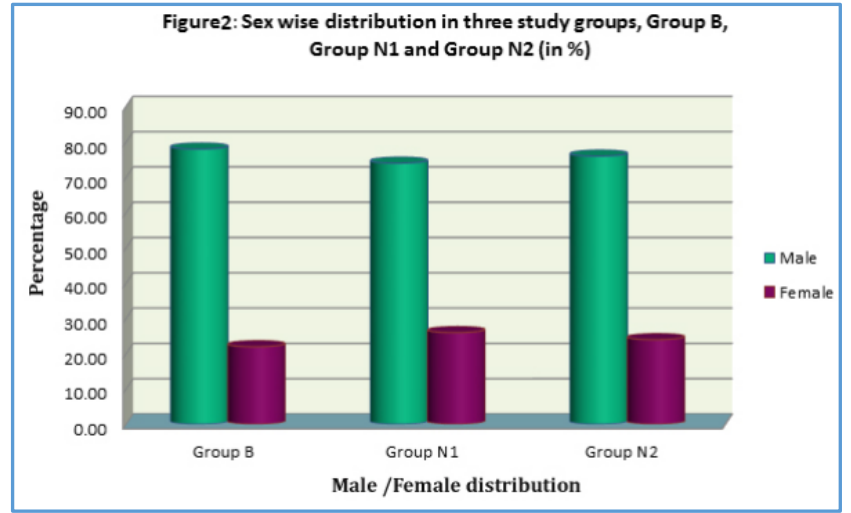

In our study group, majority of patients belonged to age group between 15 and 45 years with male predominance.

Table 1 and Figures 3, 4 depict the variables compared in terms of Sensory Block Scores, Motor Block Scores and Duration of Analgesia among three study groups. The onset of sensory block was faster in Group N1 and Group N2 with a mean onset time of 14.5 minutes (with an SD of 1.91 in Group N1 and 1.74 in Group N2), whereas in Group B it was 17.70 minutes (with an SD of 2.35), $\mathrm{p}<0.05$.

\begin{tabular}{|c|c|c|c|c|c|c|c|c|c|}
\hline \multirow{2}{*}{$\begin{array}{c}\text { Main } \\
\text { Variables }\end{array}$} & \multirow{2}{*}{$\begin{array}{c}\text { Parameters } \\
\text { Measured }\end{array}$} & \multicolumn{2}{|c|}{$\begin{array}{c}\text { Group } \\
\text { B }\end{array}$} & \multicolumn{2}{|c|}{ Group N1 } & \multicolumn{2}{|c|}{ Group N2 } & \multirow[t]{2}{*}{ F-value } & \multirow[t]{2}{*}{ P-value } \\
\hline & & Mean & SD & Mean & SD & Mean & SD & & \\
\hline \multirow{2}{*}{ Sensory Block } & Onset (in mins) & 17.70 & 2.35 & 14.50 & 1.91 & 14.50 & 1.74 & 25.2160 & $0.0001^{*}$ \\
\hline & Duration (in mins) & 342.00 & 47.66 & 687.33 & 18.37 & 692.00 & 22.19 & 1169.2812 & $0.0001^{*}$ \\
\hline \multirow{3}{*}{$\begin{array}{l}\text { Motor } \\
\text { Block }\end{array}$} & Onset (in mins) & 25.43 & 2.22 & 21.13 & 1.72 & 20.33 & 1.99 & 57.1642 & $0.0001^{*}$ \\
\hline & Duration (in mins) & 369.00 & 41.05 & 400.67 & 15.30 & 405.00 & 16.56 & 15.8495 & $0.0001^{*}$ \\
\hline & $\begin{array}{c}\text { Duration of Analgesia } \\
\text { (in mins) }\end{array}$ & 372.00 & 42.86 & 507.33 & 42.09 & 512.00 & 42.30 & 105.4161 & $0.0001^{*}$ \\
\hline
\end{tabular}

Table 1. Comparison of Three Study Groups (Group B, Group N1 and Group N2) with Sensory Block, Motor Block and Duration of Analgesia Variables

The duration of sensory block was longer in Group N2 with a mean duration of 692 minutes (with an SD of 22.19), whereas in Group N1 it was 687.33 minutes (with an SD of 18.37) and in Group B it was 342 minutes (with an SD of 47.66). The onset of motor block was faster in Group N2 with a mean onset time of 20.33 minutes (with an SD of 1.99), whereas in Group N1 it was 21.13 minutes (with an SD of 1.72) and in Group B it was 25.43 minutes (with an SD of 2.22), $\mathrm{p}<0.05$.

The duration of motor block was longer in Group N2 with a mean duration of 405 minutes (with an SD of 16.56), whereas in Group N1 it was 400.67 minutes (with an SD of 15.30) and in Group B it was 369.00 minutes (with an SD of 41.05), $\mathrm{p}<0.05$.

The duration of analgesia was longer in Group N2 with a mean duration of 512 minutes (with an SD of 42.30), whereas in Group N1 it was 507.33 minutes (with an SD of 42.09) and in Group B it was 372.00 minutes (with an SD of 42.86), $\mathrm{p}<0.05$.

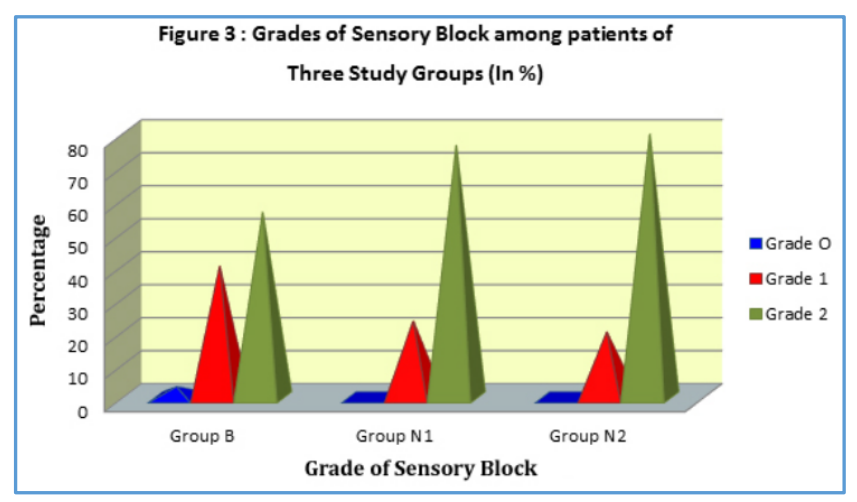



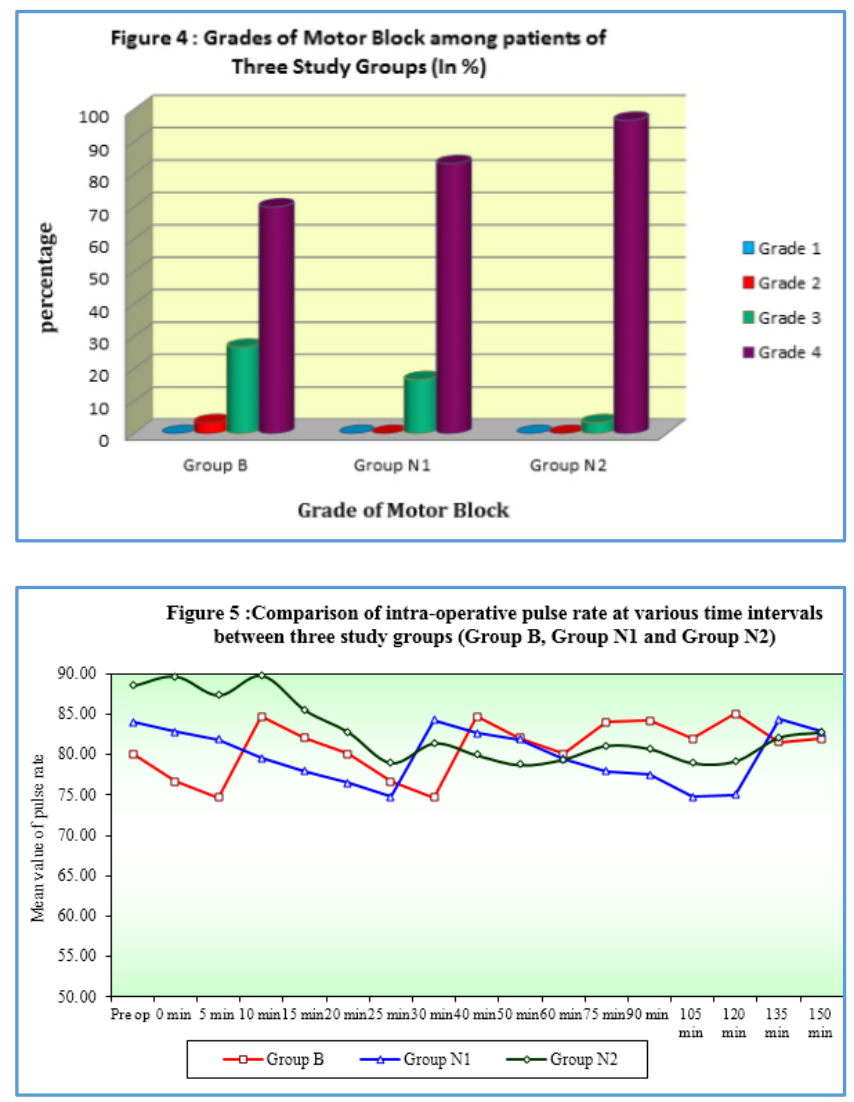

Perioperative haemodynamic parameters of blood pressure, heart rate (Figure 5 and 6) and ECG were stable. The respiratory rate and oxygen saturation were comparable between the groups. There was no complaint of difficulty in breathing or any clinical evidence of diaphragmatic palsy or pneumothorax in any patient. No complications of anaesthetic technique or drug-related adverse effects such as nausea, vomiting, pruritus or dry mouth were observed in any patient.

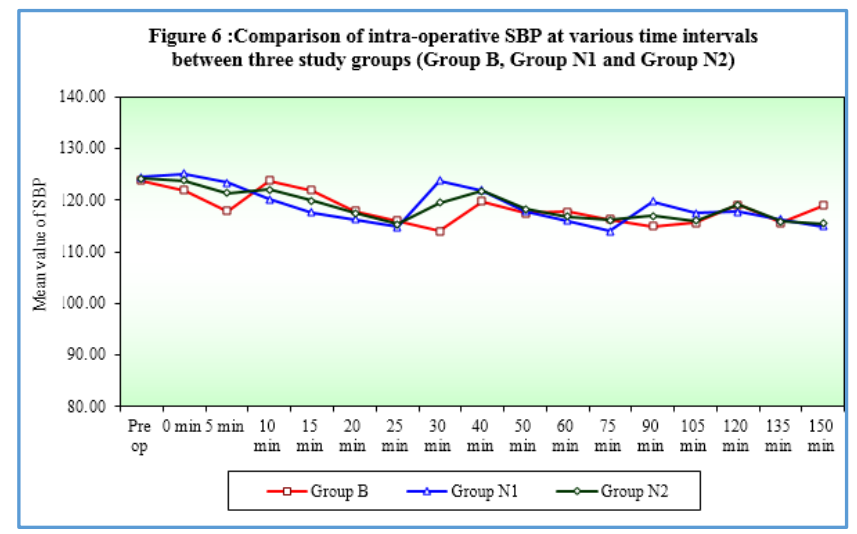

\section{DISCUSSION}

Brachial plexus blockade is commonly performed regional anaesthetic technique for forearm and hand surgeries, as it provides good surgical anaesthesia. Advantages of supraclavicular blocks include rapid onset, predictable and dense anaesthesia along with its high success rate. ${ }^{1}$

Different opioid adjuvants are added to local anaesthetic to improve the quality and duration of postoperative analgesia of peripheral nerve blocks. ${ }^{2}$
As an adjuvant to local anaesthetics nalbuphine is used in epidural, caudal and intrathecal anaesthesia, ${ }^{8}$ but after research we did not find many published data regarding the effect of Nalbuphine being used as an adjuvant to local anaesthetics in peripheral nerve block.

Nalbuphine is a mixed $\mathrm{k}$ (kappa) agonist and $\mu$-antagonist opioid with a moderate analgesic effect as compared to morphine. Its affinity to k-opioid receptors results in analgesia, sedation and cardiovascular stability with minimal respiratory depression. Other than $\mu$-opioid-based spinal and supraspinal analgesia, nalbuphine also inhibit of neuronal serotonin uptake which in turn amplify the spinal inhibitory pain pathway. ${ }^{3}$ When opiate receptors in central nervous system are stimulated, there is hyperpolarisation of the cell membrane by opening of potassium channels and closing of the sodium channels leading to inhibition of action potential transmission of ascending pain pathways. 4

Bupivacaine dose was chosen as per recommendations in the textbook ${ }^{5}$ and previous studies conducted by Casati $\mathrm{A}$ et $\mathrm{al}^{6}$ and Ambi et $\mathrm{al}^{7}$ who had taken $36 \mathrm{~mL}$ of $0.5 \%$ levobupivacaine for perivascular and perineural ultrasoundguided axillary brachial plexus block, while we took $30 \mathrm{~mL}$ of 0.5\% Bupivacaine.

In this prospective, randomised, double-blinded trial, we compared the anaesthetic and analgesic effects of two doses of Nalbuphine $(0.1 \mathrm{mg} / \mathrm{kg}$ for Group N1) and Nalbuphine $(0.2$ $\mathrm{mg} / \mathrm{kg}$ for Group N2) as an adjuvant to $0.5 \% 30 \mathrm{~mL}$ of Bupivacaine in brachial plexus block. For the third Group (Group B, Normal Saline was used as adjuvant).

The duration of Sensory Block was longer in Group N2 with a mean duration of 692 minutes (with an SD of 22.19), in Group N1 it was 687.33 minutes (with an SD of 18.37), while in Group B it was mere 342.00 minutes (with an SD of 47.66). The onset of Motor Block was faster in Group N2 with a mean onset time of 20.33 minutes (with an SD of 1.99), in Group N1 it was 21.13 minutes (with an SD of 1.72), whereas in Group B it was 25.43 minutes (with an SD of 2.22).

Similarly, the duration of Motor Block was longer in Group N2 with a mean duration of 405 minutes (with an SD of 16.56), in Group N1 it was 400.67 minutes (with an SD of 15.30), while in Group B it was 369.00 minutes (with an SD of 41.05).

A similar study conducted upon eighty patients by Chatrath et al, to analyse the role of Nalbuphine for prolongation and quality of postoperative analgesia yielded similar results. ${ }^{9}$

Viel et al showed that injection Buprenorphine into the brachial plexus sheath using supraclavicular technique is an efficient way to control postoperative pain after upper limb surgery. ${ }^{10}$

Abdelhaq et al had also used $20 \mathrm{mg}$ Nalbuphine as adjuvant to $25 \mathrm{~mL}$ of $0.5 \%$ Bupivacaine for supraclavicular brachial plexus block for upper arm surgeries and concluded that Nalbuphine not only increased the duration of both sensory and motor block significantly, it also prolonged postoperative analgesia significantly. ${ }^{11}$

In the present study, we too observed the enhanced duration of sensory and motor block along with duration of analgesia in both doses $(0.1 \mathrm{mg} / \mathrm{kg}$ and $0.2 \mathrm{mg} / \mathrm{kg})$ of Nalbuphine, which were statistically significant. 
Our study results correlated well with Veena Chatrath, et al who compared the postoperative analgesic effect of both Tramadol and Nalbuphine when used epidurally in patients undergoing lower limb orthopaedic surgery and concluded that Nalbuphine group had better quality of surgical analgesia, minimum incidence of side-effects and complications. ${ }^{9}$ Culebras et al compared the three different doses $(0.2 \mathrm{mg}, 0.8 \mathrm{mg}$ and $1.6 \mathrm{mg}$ ) of Nalbuphine given intrathecally among study group of 90 obstetric patients undergoing caesarean section and found that $0.8 \mathrm{mg}$ as the most effective dosage. ${ }^{12}$

Shehla Shakooh et al studied intrathecal Hyperbaric Bupivacaine $(0.5 \%)$ with Nalbuphine $0.8 \mathrm{mg}$ as an adjuvant for various lower abdominal and lower limb surgeries and compared its postoperative analgesic effect to Hyperbaric Bupivacaine $(0.5 \%)$ concluded that Nalbuphine as an adjuvant shortens the onset, prolongs duration of sensory and motor blockade, provides effective postoperative analgesia and desirable sedation intraoperatively without any major adverse effects. ${ }^{13}$

Study conducted by Maha MI et al, on the effect of Nalbuphine and compared with tramadol as adjuvants to Lidocaine in intravenous regional anaesthesia concluded that Nalbuphine was proved to be more effective than Tramadol in prolonging the duration of postoperative analgesia. 14

\section{CONCLUSION}

The present study demonstrates that the addition of 0.1 $\mathrm{mg} / \mathrm{kg}$ and $0.2 \mathrm{mg} / \mathrm{kg}$ nalbuphine to bupivacaine in supraclavicular brachial plexus block in patients undergoing forearm and hand surgeries is associated with a significant increase in the duration of both sensory and motor block. Nalbuphine, in both the doses as an adjuvant was found to be equipotent as it not only enhances the quality of blocks, duration of postoperative analgesia, but also reduces the requirement of rescue analgesics without any appreciable side effects.

\section{ACKNOWLEDGEMENT}

We acknowledge the co-operation rendered by the Department of Orthopaedics, Anaesthesia colleagues and Statistician in conducting this study.

\section{REFERENCES}

[1] Klein SM, Nielsen KC. Brachial plexus blocks: infusions and other mechanisms to provide prolonged analgesia. Curr Opin Anaesthesiol 2003;16(4):393-9.

[2] Kaabachi O, Ouezini R, Koubaa W, et al. Tramadol as an adjuvant to lidocaine for axillary brachial plexus block. Anesth Analg 2009;108(1):367-70.

[3] Gear RW, Miaskowski C, Gordon NC, et al. The kappa opioid nalbuphine produces gender-and dosedependent analgesia and antianalgesia in patients with postoperative pain. Pain 1999;83(2):339-45.
[4] Acharya R, Jena M, Mishra S, et al. Effect of butorphanol versus placebo as adjuvant to bupivacaine for supraclavicular brachial plexus blockade. Int J Appl Pharm 2014;6:8-10.

[5] Berde CB, Strichartz GR. Local anesthetics. In: Miller RD, Cohen NH, Eriksson LI, et al. (eds). Miller's anesthesia. $8^{\text {th }}$ edn. Philadelphia: Elsevier Saunders, 2010:1028-55.

[6] Casati A, Borghi B, Fanelli G, et al. Interscalene brachial plexus anesthesia and analgesia for open shoulder surgery: a randomized, double-blinded comparison between levobupivacaine and ropivacaine. Anesth Analg 2003;96(1):253-9.

[7] Ambi U, Bhanupriya P, Hulkund SY, et al. Comparison between perivascular and perineural ultrasoundguided axillary brachial plexus block using levobupivacaine: a prospective, randomised clinical study. Indian J Anaesth 2015;59(10):658-63.

[8] Yeh YC, Lin TF, Lin FS, et al. Combination of opioid agonist and agonist-antagonist: patient-controlled analgesia requirement and adverse events among different-ratio morphine and nalbuphine admixtures for postoperative pain. Br J Anaesth 2008;101(4): 542-8.

[9] Chatrath V, Attri JP, Bala A, et al. Epidural nalbuphine for postoperative analgesia in orthopedic surgery. Anesth Essays Res 2015;9(3):326-30.

[10] Viel EJ, Eledjam JJ, De La Coussaye JE, et al. Brachial plexus block with opioids for postoperative pain relief: comparison between buprenorphine and morphine. Reg Anesth 1989;14(6):274-8.

[11] Abdelhaq MM, Elramely MA. Effect of nalbuphine as adjuvant to bupivacaine for ultrasound-guided supraclavicular brachial plexus block. Open J Anesthesiol 2016;6:20-6.

[12] Culebras X, Gaggero G, Zatloukal J, et al. Advantages of intrathecal nalbuphine, compared with intrathecal morphine, after cesarean delivery: an evaluation of postoperative analgesia and adverse effects. Anesth Analg 2000;91(3):601-5.

[13] Shakooh S, Bhosle P. Intrathecal nalbuphine: an effective adjuvant for post operative analgesia. Innovative Journal of Medical and Health Science 2014;4:79-82.

[14] Youssef MMI, ElZayyat NS. Lidocaine-nalbuphine versus lidocaine-tramadol for intravenous regional anesthesia. Ain-Shams Journal of Anaesthesiology 2014;7(2):198-204. 